\title{
Pharmacological Effects of Ginseng on Liver Functions and Diseases: A Minireview
}

\author{
Nguyen Huu Tung, ${ }^{1}$ Takuhiro Uto, ${ }^{1}$ Osamu Morinaga, ${ }^{1}$ \\ Young Ho Kim, ${ }^{2}$ and Yukihiro Shoyama ${ }^{1}$ \\ ${ }^{1}$ Faculty of Pharmaceutical Sciences, Nagasaki International University, 2825-7 Huis Ten Bosch, Sasebo, Nagasaki 859-3298, Japan \\ ${ }^{2}$ College of Pharmacy, Chungnam National University, Daejeon 305-764, Republic of Korea
}

Correspondence should be addressed to Yukihiro Shoyama, shoyama@niu.ac.jp

Received 8 June 2012; Accepted 10 August 2012

Academic Editor: Chun-Su Yuan

Copyright ( $) 2012$ Nguyen Huu Tung et al. This is an open access article distributed under the Creative Commons Attribution License, which permits unrestricted use, distribution, and reproduction in any medium, provided the original work is properly cited.

\begin{abstract}
Ginseng, an ancient and famous medicinal herb in the Orient, has been used as a valuable tonic and for the treatment of various diseases including hepatic disorders. Ginseng saponins, commonly known as ginsenosides, are principal constituents and have believed to be responsible for multiple ginseng health benefits. There are more 40 ginsenosides isolated from ginseng. To date, treatment options for common liver diseases such as cirrhosis, fatty liver, and chronic hepatitis remain problematic. In this regard, ginseng extracts and individual ginsenosides have shown a wide array of beneficial role in the regulation of regular liver functions and the treatment of liver disorders of acute/chronic hepatotoxicity, hepatitis, hepatic fibrosis/cirrhosis, hepatocellular carcinoma, and so on in various pathways and mechanisms. In this paper, we first outline the pharmacological effects of ginseng and ginsenosides on the liver functions.
\end{abstract}

\section{Introduction}

Botanical medicines have been applied for the treatment of various human diseases with thousands of years of history in Asia and are sharing a large market in the form of drugs, dietary supplements, and foods. In the west, botanical medicines are categorized as complementary/alternative medicines, dietary supplements, or foods. Ginseng, referred to as the root of Panax ginseng C.A. Meyer (Araliaceae), is one of the most valuable medicinal plants, particularly in Korea, China, and Japan [1].

Ginseng has been used as a valuable tonic and for the treatment of various diseases $[1,2]$. Traditionally, ginseng has been processed to make white ginseng (air-drying after harvest) and red ginseng (steaming or heat process) to enhance its preservation and efficacy. In which, red ginseng is more common as an herbal medicine than white ginseng because steaming induces changes in the chemical constituents and enhances the biological activities of ginseng $[1,2]$. The pharmacological properties of ginseng are mainly attributed to ginseng saponins, commonly called ginsenoisdes, the major and bioactive constituents $[3,4]$. With the development of modern chromatography, there are more 40 ginsenoisdes such as ginsenoisdes $\mathrm{Rb}_{1}, \mathrm{Rb}_{2}, \mathrm{Rg}_{1}, \mathrm{Rd}$, and Re identified from ginseng up to date $[4,5]$. Except for ginsenoisde Ro and polyacetylene ginsenoisde Ro belonging to oleananetype saponins, other ginsenoisdes are of dammarane-type saponins and classified into protopanaxadiol and protopanaxatriol groups depending on whether or not hydroxyl group at C-6 of aglycon moieties exist (Figure 1). On the other hand, ginseng and ginsenoisdes have been found to exhibit multiple pharmacological activities via different mechanisms and pathways in vitro, in vivo, and clinical models [2-4]. Having been well documented, there are hundreds of research papers as well as extensive reviews spotlighted on individual topics, that is, cardiovascular $[6,7]$, central nervous [8], and immune systems [9, 10]. However, the pharmacological effects of ginseng/ginsenoisdes on liver disorders have not been systematically reviewed. The purpose of this paper is to introduce the multifaceted pharmacological effects and related mechanisms of ginseng/ginsenoisdes on hepatic functions. 


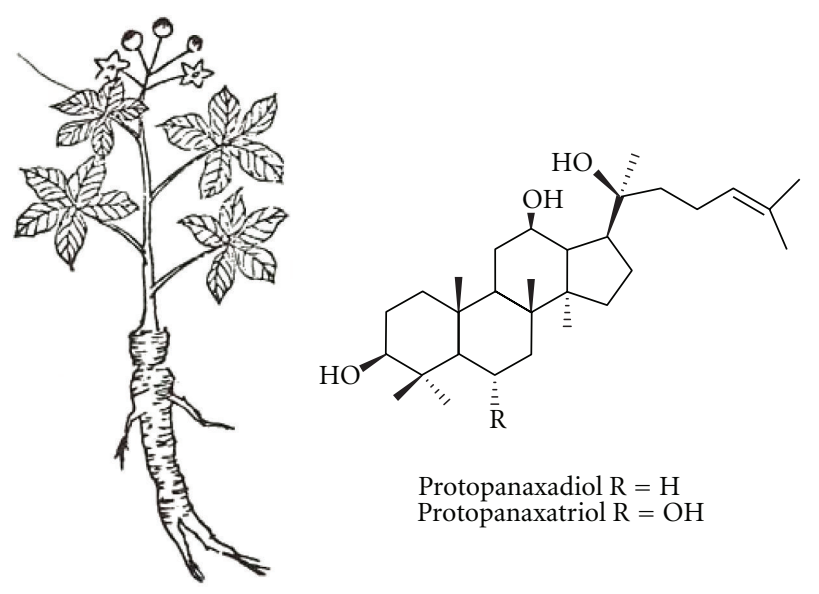

Figure 1: Panax ginseng C.A. Mayer and ginsenoisde skeletons.

\section{Liver Diseases and Herbal Medicine in the Treatment of Liver Diseases}

Liver diseases represent a major health burden worldwide, with liver cirrhosis being the ninth leading cause of death in western countries [11]. Chronic viral hepatitis B and C, alcoholic liver disease, nonalcoholic fatty liver disease, and hepatocellular carcinoma are the major entities and many problems remain unresolved. Therapies developed along the principles of western medicine are often limited in efficacy, carry the risk of adverse effects, and are often too costly, especially for the developing world. Therefore, treating liver diseases with plant-derived products which are accessible and do not require laborious pharmaceutical synthesis seems highly attractive. Furthermore, in spite of the advances in conventional medicine in the last decades, professionals and the lay public of developed countries pay increasing attention to phytomedicine. Several recent surveys from Europe and the United States have demonstrated a sharp rise in the use of botanical drugs within a few years, and up to $65 \%$ of patients with liver disease take herbal preparations [12-15].

\section{Protective Effect of Ginseng Extracts and Ginsenoisdes on
Hepatic Functions and Diseases}

\subsection{Ginseng Extracts}

\subsubsection{Multiple Efficacies}

General Hepatotoxicity. Acute/chronic hepatotoxicity suffers from drugs used, alcohol, contaminant, and poisoning and may be incidence of liver diseases including liver hepatitis, cirrhosis/fibrosis, and hepatocellular carcinoma (HCC). Ginseng extracts have been reported to show protective effects on hepatocytes in vitro and liver injury in various animal, and clinical models induced by a wide variety of hepatotoxins including hydrogen peroxide $\left(\mathrm{H}_{2} \mathrm{O}_{2}\right)$ [16], alcohol [17, 18], carbon tetrachloride $\left(\mathrm{CCl}_{4}\right)[16,19-22]$, aflatoxin $\mathrm{B}_{1}[23,24]$, fumonisins [24], tert-butylhydroperoxide (t-BHP) [25], cadmium chloride $\left(\mathrm{CdCl}_{2}\right)$ [26, 27], benzo[alpha]pyrene (BP) [28], 2,3,7,8tetrachlorodibenzo- $p$-dioxin [29], lipopolysaccharide [30], diethylnitrosamine [31], galactosamine (GalN) [32-34], bromobenzene [35], xenobiotics [36], and mercuric chloride [37]. Ginseng has also found to protect liver cells from radiation [38] and viral hepatitis [39].

Liver Regeneration and Transplantation. Ginseng is beneficial in the treatment of acute graft-versus-host disease, a rare complication after liver transplantation with an extremely poor prognosis [40]. On the other hand, red ginseng is markedly effective in liver regeneration after partial hepatectomy in rats (70\%) [41] and dogs (40\%) [42] by increase of the liver weight and acceleration of hepatocyte proliferation.

Fatty Liver and Liver Glycogen. Liver and adipose tissue play an important role in both lipid and sugar metabolism. It has been found that ginseng has effects on lipid and sugar when administrated to rats in vivo [43, 44]. Hepatic cholesterol and triglyceride contents are decreased and phospholipid is increased by ginseng administration in the high cholesterol diet-fed rats, supporting to improvement of the fatty liver [45]. In another study, ginseng produces a decrease of hepatic glycogen content in fat diet-fed rats [44].

Liver Cancer. HCC is one of the most frequent tumor types worldwide. It is the fifth most common cancer and the third leading cause of cancer death [46]. Ginseng has been evaluated as a chemopreventive therapy against HCC [4749]. Results of epidemiological studies of ginseng intake and cancer cases (4600 patients) show that those who take ginseng are less likely to contract various cancers such as cancer of the stomach, liver, and lung than those who do not take it, and that increased intake leads to a lesser ratio of danger, proving its usefulness for primary prevention [50, 51]. In a clinical survey, the prolonged administration of red ginseng extract significantly inhibits the incidence of hepatoma and also proliferation of pulmonary tumors induced by aflatoxin $\mathrm{B}_{1}$ and urethane [52]. Recently, another clinical research reported that ginseng administration induced a significant improvement in liver function tests, decreased the tumor marker levels, and decreased the viral titers in HCV (hepatitis $\mathrm{C}$ virus) patients, supporting powerful therapeutic effects against HCV and liver cancer [39].

\subsubsection{Mechanisms of Actions}

Antioxidation. The mechanisms which provide ginseng's hepatoprotective effects are closely attributed to antioxidation properties. Ginseng enhanced the antioxidant defense mechanism [53] and increased self-antioxidant enzyme activities of superoxide dismutase (SOD), catalase (CAT), glutathione peroxidase $(\mathrm{GPx})$, glutathione reductase (GR), glutathione-S-transferase (GSH), and heme oxygenase-1 in the aged-rat liver [54] and hepatotoxins-induced liver damages in rats $[20,23,26,28,30,55,56]$. Ginseng treatments inhibited oxidative stress damage such as lipid peroxidation 
$[16,26,28,54]$, malondialdehyde [23], thiobarbituric acid reactive substance $[23,30,56]$, alanine aminotransferase (ALT), aspartate aminotransferase (AST), and lactate dehydrogenase $(\mathrm{LDH})[25,28,39,42,57]$. The protective effects have been histologically and histochemically monitored. Recently, further molecular mechanism studies found that ginseng suppresses mitogen-activated protein kinase (MAPK) signals [16], nuclear factor-kappa B (NF-kB), and inducible nitric oxide synthase (iNOS) protein expression $[30,56]$.

Anti-Inflammation. Inflammatory effects of ginseng have been responsible for the liver protection. Ginseng suppressed the production of inflammatory cytokines (IL-1 $\beta$, IFN$\gamma)$ and chemokines (MCP-1, MIP- $2 \beta, \mathrm{KC}$ ) in $\mathrm{CCl}_{4}$-treated mice [55]. Recently, ginseng was found to inhibit tumor necrosis factor alpha (TNF- $\alpha$ )-stimulated NF-kB activation and further suppressed the gene expression of iNOS and cyclooxygenase-2 (COX-2) in HepG-2 cells [58].

Inhibition of Cytochrome P450 (CYP). Ginseng and ginsenoisdes may have selectively inhibitory effects on CYP activities. In a recent animal study, ginseng was found to inhibit specifically benzo [alpha]pyrene-induced CYP1A1 activation by downregulation of the gene expression [28] Another study also indicated that the inhibitory effects of ginseng on CYP enzymes take part in the protection of rat liver microsomes against $\mathrm{CCl}_{4}$ [21]. Further investigation into ginseng metabolism suggested that ginsenoisde metabolites like compound $\mathrm{K}$, produced after oral administration, are responsible for the inhibition of the CYP-mediated metabolism rather than naturally occurring ginsenoisdes [59]. These evidence may explain some of the hepatoprotective effects of ginseng against hepatotoxins.

\subsection{Ginsenoisdes}

3.2.1. Ginsenoisde $R b_{1}$. Ginsenoisde $\mathrm{Rb}_{1}$, a major ginseng saponin, protects hepatocytes against t-BHP and $\mathrm{CCl}_{4}$ by regulating inducible hepatic enzymes of ALT and AST $[22,60]$ and may be associated with modulating liver CYP activation [61] and protein phosphorylations [62]. In a recent study, ginsenoisde $\mathrm{Rb}_{1}$ significantly inhibits liver fibrosis by inhibiting activation, proliferation, and expression of collagen, transforming growth factor- $\beta_{1}$ (TGF1), matrix metalloproteinase (MMP)-2, and tissue inhibitor of metalloproteinase (TIMP)-1 in hepatic stellate cells, the major cause of liver fibrosis, at $10-80 \mu \mathrm{g} / \mathrm{mL}$ [63]. More recently, ginsenoisde $\mathrm{Rb}_{1}$ is found to inhibit TNF- $\alpha$ mediated NF-kB transcriptional activity in HepG2 cells with $\mathrm{IC}_{50}$ of $27.45 \mu \mathrm{M}$ and gene expression of iNOS and COX-2 inducible inflammatory enzymes [58].

Ginsenoisde $\mathrm{Rb}_{1}$ is beneficial against fatty/high cholesterol liver as well as hepatic triglycerides in rats fed on high-fat diet, supporting that ginsenoisde $R b_{1}$ may be involved in lipid metabolism by regulating the activity of microsomal CYP monooxygenase and 3-hydroxy-3-methyl glutaryl coenzyme A (HMG-CoA) reductase [64-66].
3.2.2. Ginsenoisde $R g_{1}$. Ginsenoisde $\operatorname{Rg}_{1}$, also one of the most abundant ginseng components of ginseng, significantly improves the extent of liver fibrosis in rat induced by thioacetamide as reducing the serum levels of fibrotic markers of ALT, AST, and alkaline phosphatase and hepatic hydroxyproline content [67]. In addition, in cultured hepatic stellate cells, ginsenoisde $\mathrm{Rg}_{1}$ markedly inhibits cell proliferation, activation and formation of reactive oxygen species, and the NF-kB activity [67]. Also, ginsenoisde $\mathrm{Rg}_{1}$ is found to inhibit TNF- $\alpha$-mediated NF-kB transcriptional activity in HepG2 cells with $\mathrm{IC}_{50}$ of $28.14 \mu \mathrm{M}$ and gene expression of iNOS and COX-2 inducible inflammatory enzymes [58].

Recently, ginsenoisde $\mathrm{Rg}_{1}$ suppresses hepatic glucose production via AMP-activated protein kinase (AMPK) activation in HepG2 cells [68].

3.2.3. Ginsenoisdes $R d, R e$, and $R o$. Yuan et al. reported that ginsenoisde $\operatorname{Re}(40 \mathrm{mg} / \mathrm{kg})$ attenuates alcoholic fatty liver disease through regulation of AMPK and mitogen-activated protein kinase (MAPK) pathways in alcoholic-fed ICR mice [69]. In another related study, the same group revealed ginsenoisde Re to lower blood glucose and lipid level via activation of AMPK pathway in HepG2 cells and high-fat diet fed mice, suggesting therapeutic benefits on type 2 diabetic patients with insulin resistance and dyslipidemia [70].

Ginsenoisde Rd is recently found to inhibit TNF- $\alpha$ mediated NF-kB transcriptional activity in HepG2 cells with IC $_{50}$ of $12.05 \mu \mathrm{M}$ and gene expression of iNOS and COX-2 inducible inflammatory enzymes [58].

Ginsenoisde Ro, an oleanane-type ginsenoisde, (50 and $200 \mathrm{mg} / \mathrm{kg}$, p.o.) shows the protective effects on GalN and $\mathrm{CCl}_{4}$-induced acute hepatitis rats as monitored by the level of inducible hepatic enzymes of glutamic oxaloacetic transaminase and glutamic pyruvic transaminase [32].

3.2.4. Ginsenoisdes $R g_{2}, R g_{3}$, and $M_{1}$. Ginsenoisdes $R_{2}$ and $\mathrm{Rg}_{3}$ represent major components of red ginseng [5]. Ginsenoisde $\mathrm{M}_{1}$ or compound $\mathrm{K}$ is an intestine bacterial metabolite of the ginseng protopanaxadiol-type saponins. In a recent study, ginsenoisde $\mathrm{Rg}_{2}$ significantly inhibits hepatic glucose production in HepG2 cells via activation of AMPK pathway like ginsenoisde Re [71]. Meanwhile, ginsenoisdes $\mathrm{Rg}_{3}$ and $\mathrm{M}_{1}$ have well evaluated for their cancer chemopreventative against several cancer cell lines and tumors in vitro and in vivo including leukemia, colon, and HCC [51, 72-74]. More recently, ginsenoisde $\mathrm{Rg}_{3}$ at 25$200 \mu \mathrm{g} / \mathrm{mL}$ shows significantly antiproliferative effects on liver cancer cells (SMMC-7721, Hep1-6, and HepG2) and hepatocellular tumor growth in vivo by inhibiting cancer cell proliferation and promoting cancer cell apoptosis [75, 76]. In another research, ginsenoisde $M_{1}$ exhibits antihepatocellular carcinoma activity by augmenting apoptosis via Bid-mediated mitochondrial pathways [77]. On the other hand, ginsenoisde $M_{1}$ has beneficial role against hyperlipidemia and obesity by attenuating hepatic lipid accumulation via AMPK activation in human hepatoma cells [78]. In addition, ginsenoisdes $\mathrm{Rg}_{3}$ and $\mathrm{M}_{1}$ are also 
involved in general hepatoprotection against hepatotoxins $[60,79]$.

\section{Application of Ginseng to Hepatic Diseases}

Liver disorders are among the most serious sicknesses in the population. Together with healthy lifestyle recommendation, therapies for hepatic diseases are necessary and need be more effective and economical [80]. Botanical medicines have been used traditionally worldwide for the prevention and treatment of liver disease. By now, herbal products are increasingly consumed, mainly in chronic liver disease. Turmeric (Curcuma longa), green tea (Camellia sinensis), garlic (Allium sativa), licorice (Glycyrrhiza spp.), especially milk thistle (Silybum marianum) with have been well researched and recognized as phytotherapies for use in a wide variety of prevention and treatment of hepatic diseases [81, 82].

Based on compelling experimental evidence, ginseng has an interesting hepatoprotective profile. From a therapeutic standpoint, ginseng could provide an alternative phytomedicine and another option for the preventative therapy and treatments of common liver diseases such as cirrhosis, fatty liver, and chronic hepatitis in addition to a well-known tonic and in forms of healthy foods.

\section{Conclusions}

Ginseng and its principal components, ginsenoisdes, have shown a wide array of pharmacological activities including beneficial role in the regulation of liver functions and the treatment of liver disorders of acute/chronic hepatotoxicity, hepatitis, hepatic fibrosis/cirrhosis, liver hepatectomy, liver transplantation, and even liver failure and HCC. The possible activity pathways of the actions have been also investigated. There is increasing attention to the effects of ginseng on the liver functions. However, more detailed molecular mechanisms of the activities of ginseng/ginsenoisdes as well as further efficacy and safety studies remain to be explored.

It is another important area for further research and development to combine ginseng with other liver active drugs to investigate their possible synergic efficacy and preferably pharmacological properties.

Taken together, accumulating evidence supports the potential of ginseng in the treatment of the hepatic diseases and further studies will facilitate their application so far.

\section{Acknowledgment}

N. H. Tung is supported by JSPS (the Japan Society for the Promotion of Science).

\section{References}

[1] T. K. Yun, "Brief introduction of Panax ginseng C.A. Meyer," Journal of Korean Medical Science, vol. 16, supplement, pp. S3S5, 2001.

[2] J. D. Park, D. K. Rhee, and Y. H. Lee, "Biological activities and chemistry of saponins from Panax ginseng C. A. Meyer," Phytochemistry Reviews, vol. 4, no. 2-3, pp. 159-175, 2005.
[3] E. Ernst, "Panax ginseng: an overview of the clinical evidence," Journal of Ginseng Research, vol. 34, no. 4, pp. 259-263, 2010.

[4] K. T. Choi, "Botanical characteristics, pharmacological effects and medicinal components of Korean Panax ginseng C A Meyer," Acta Pharmacologica Sinica, vol. 29, no. 9, pp. 11091118, 2008.

[5] L. W. Qi, C. Z. Wang, and C. S. Yuan, "Isolation and analysis of ginseng: advances and challenges," Natural Product Reports, vol. 28, no. 3, pp. 467-495, 2011.

[6] M. Karmazyn, M. Moey, and X. T. Gan, "Therapeutic potential of ginseng in the management of cardiovascular disorders," Drugs, vol. 71, no. 15, pp. 1989-2008, 2011.

[7] C. Buettner, G. Y. Yeh, R. S. Phillips, M. A. Mittleman, and T. J. Kaptchuk, "Systematic review of the of ginseng on cardiovascular risk factors," Annals of Pharmacotherapy, vol. 40, no. 1, pp. 83-95, 2006.

[8] K. Radad, G. Gille, L. Liu, and W. D. Rausch, "Use of ginseng in medicine with emphasis on neurodegenerative disorders," Journal of Pharmacological Sciences, vol. 100, no. 3, pp. 175$186,2006$.

[9] D. C. W. Lee and A. S. Y. Lau, "Effects of Panax ginseng on tumor necrosis factor- $\alpha$-mediated inflammation: a minireview," Molecules, vol. 16, no. 4, pp. 2802-2816, 2011.

[10] A. S. Attele, J. A. Wu, and C. S. Yuan, "Ginseng pharmacology: multiple constituents and multiple actions," Biochemical Pharmacology, vol. 58, no. 11, pp. 1685-1693, 1999.

[11] W. R. Kim, R. S. Brown, N. A. Terrault, and H. El-Serag, "Burden of liver disease in the United States: summary of a workshop," Hepatology, vol. 36, no. 1, pp. 227-242, 2002.

[12] P. A. G. M. De Smet, "Herbal remedies," The New England Journal of Medicine, vol. 347, no. 25, pp. 2046-2056, 2002.

[13] R. C. Kessler, R. B. Davis, D. F. Foster et al., "Long-term trends in the use of complementary and alternative medical therapies in the United States," Annals of Internal Medicine, vol. 135, no. 4, pp. 262-268, 2001.

[14] D. B. Strader, B. R. Bacon, K. L. Lindsay et al., "Use of complementary and alternative medicine in patients with liver disease," American Journal of Gastroenterology, vol. 97, no. 9, pp. 2391-2397, 2002.

[15] K. D. Flora, H. R. Rosen, and K. G. Benner, "The use of naturopathic remedies for chronic liver disease," American Journal of Gastroenterology, vol. 91, no. 12, pp. 2654-2655, 1996.

[16] M. J. Bak, M. Jun, and W. S. Jeong, "Antioxidant and hepatoprotective of the red ginseng essential oil in $\mathrm{H}_{2} \mathrm{O}_{2}$-treated HepG2 cells and $\mathrm{CCl}_{4}$-treated mice," International Journal of Molecular Sciences, vol. 13, no. 2, pp. 2314-2330, 2012.

[17] M. Zuin, P. M. Battezzati, M. Camisasca, D. Riebenfeld, and M. Podda, "Effects of a preparation containing a standardized ginseng extract combined with trace elements and multivitamins against hepatotoxin-induced chronic liver disease in the elderly," Journal of International Medical Research, vol. 15, no. 5, pp. 276-281, 1987.

[18] H. M. Park, H. K. Go, A. R. Mun et al., "n red ginseng attenuate an ethanol-induced hepatocyte toxicity, by increasing the level of $\mathrm{Mg}^{2+}$ and suppression of the MAPK pathway," in Proceedings of the Spring International Ginseng Conference, p. 93, The Korean Society of Ginseng, Jeju, Korea, April 2012.

[19] E. S. El Denshary, M. A. Al-Gahazali, F. A. Mannaa, H. A. Salem, N. S. Hassan, and M. A. Abdel-Wahhab, "Dietary honey and ginseng protect against carbon tetrachlorideinduced hepatonephrotoxicity in rats," Experimental and Toxicologic Pathology, http://dx.doi.org/10.1016/j.etp.2011.01.012. In press. 
[20] H. F. Chang, Y. H. Lin, C. C. Chu, S. J. Wu, Y. H. Tsai, and J. C. J. Chao, "Protective effects of Ginkgo biloba, Panax ginseng, and Schizandra chinensis extract on liver injury in rats," American Journal of Chinese Medicine, vol. 35, no. 6, pp. 995-1009, 2007.

[21] H. J. Kim, Y. J. Chun, J. D. Park, S. I. Kim, J. K. Roh, and T. C. Jeong, "Protection of rat liver microsomes against carbon tetrachloride-lnduced lipid peroxidation by red ginseng," Planta Medica, vol. 63, no. 5, pp. 415-418, 1997.

[22] T. C. Jeong, H. J. Kim, J. I. Park et al., "Protective effects of red ginseng saponins against carbon tetrachloride-induced hepatotoxicity in Sprague Dawley rats," Planta Medica, vol. 63, no. 2, pp. 136-140, 1997.

[23] Y. S. Kim, Y. H. Kim, J. R. Noh, E. S. Cho, J. H. Park, and H. Y. Son, "Protective effect of korean red ginseng against aflatoxin $\mathrm{B}_{1}$-induced hepatotoxicity in rat," Journal of Ginseng Research, vol. 35, no. 2, pp. 243-249, 2011.

[24] M. A. Abdel-Wahhab, N. S. Hassan, A. A. El-Kady et al., "Red ginseng extract protects against aflatoxin $B_{1}$ and fumonisinsinduced hepatic pre-cancerous lesions in rats," Food and Chemical Toxicology, vol. 48, no. 2, pp. 733-742, 2010.

[25] H. J. Lee, J. H. Kim, S. Y. Lee, J. H. Park, and G. S. Hwang, "Processed ginseng protects t-BHP-induced oxidative damage in HepG2 cells," in Proceedings of the Spring International Ginseng Conference, p. 99, The Korean Society of Ginseng, Jeju, Korea, April 2012.

[26] R. Shukla and M. Kumar, "Role of Panax ginseng as an antioxidant after cadmium-induced hepatic injuries," Food and Chemical Toxicology, vol. 47, no. 4, pp. 769-773, 2009.

[27] A. Karadeniz, M. Cemek, and N. Simsek, "The effects of Panax ginseng and Spirulina platensis on hepatotoxicity induced by cadmium in rats," Ecotoxicology and Environmental Safety, vol. 72, no. 1, pp. 231-235, 2009.

[28] S. I. Gum, S. J. Jo, S. H. Ahn et al., "The potent protective effect of wild ginseng (Panax ginseng C.A. Meyer) against benzo $[\alpha]$ pyrene-induced toxicity through metabolic regulation of CYP1A1 and GSTs," Journal of Ethnopharmacology, vol. 112, no. 3, pp. 568-576, 2007.

[29] H. C. Lee, S. G. Hwang, Y. G. Lee et al., "In vivo effects of Panax ginseng extracts on the cytochrome P450dependent monooxygenase system in the liver of $2,3,7,8$ tetrachlorodibenzo-p-dioxin-exposed guinea pig," Life Sciences, vol. 71, no. 7, pp. 759-769, 2002.

[30] K. S. Kang, N. Yamabe, H. Y. Kim, and T. Yokozawa, "Effect of sun ginseng methanol extract on lipopolysaccharide-induced liver injury in rats," Phytomedicine, vol. 14, no. 12, pp. 840$845,2007$.

[31] X. G. Wu, D. H. Zhu, and X. Li, "Anticarcinogenic effect of red ginseng on the development of liver cancer induced by diethylnitrosamine in rats," Journal of Korean Medical Science, vol. 16, pp. S61-65, 2001.

[32] H. Matsuda, K. I. Samukawa, and M. Kubo, "Anti-hepatitic activity of ginsenoside Ro," Planta Medica, vol. 57, no. 6, pp. 523-526, 1991.

[33] H. Hikino, Y. Kiso, J. Kinouchi, S. Sanada, and J. Shoji, "Antihepatotoxic actions of ginsenosides from Panax ginseng roots," Planta Medica, vol. 51, no. 1, pp. 62-64, 1985.

[34] J. H. Song, M. J. Park, E. Kim, and Y. C. Kim, "Effects of Panax ginseng on galactosamine-induced cytotoxicity in primary cultured rat hepatocytes," Yakhak Hoeji, vol. 34, no. 5, pp. 341-347, 1990.

[35] K. Huh, B. S. Jang, and J. M. Park, "Protective effect of ginseng on bromobenzene-induced hepatotoxicity in mice," Korean Journal of Ginseng Science, vol. 12, no. 2, pp. 114-120, 1988.
[36] F. C. Lee, J. K. Park, E. K. Kim, J. H. Ko, J. S. Lee, and K. Y. Kim, "The role of Panax ginseng in detoxification of xenobiotics," in Proceedings of the 4th International Ginseng Symposium, Korean Society of Ginseng, Seoul, Korea, 1984.

[37] P. N. Saxena and K. Mahour, "Analysis of hepatoprotection by Panax ginseng following mercuric chloride intoxication in albino rat," in Proceedings of the 9th International Ginseng Symposium, Korean Society of Ginseng, Chungnam, Korea, 2006.

[38] T. S. Kim, Y. J. Kim, S. A. Jang, K. H. Yang, N. K. Seung, and E. H. Sohn, "Protective effects of red ginseng against radiationinduced hepatotoxicity in mice," in Proceedings of the Spring International Ginseng Conference, p. 100, The Korean Society of Ginseng, Jeju, Korea, April 2012.

[39] M. A. Abdel-Wahhab, K. Gamil, A. A. El-Kady, A. A. ElNekeety, and K. M. Naguib, "Therapeutic effects of Korean red ginseng extract in Egyptian patients with chronic liver diseases," Journal of Ginseng Research, vol. 35, no. 1, pp. 6979, 2011.

[40] X. Xu, Q. Ling, Q. Wei et al., "Korean red ginseng: a new approach for the treatment of graft-versus-host disease after liver transplantation," Transplantation Proceedings, vol. 43, no. 7, pp. 2651-2655, 2011.

[41] Y. S. Kwon and K. H. Jang, "The effect of Korean red ginseng on liver regeneration after $70 \%$ hepatectomy in rats," Journal of Veterinary Medical Science, vol. 66, no. 2, pp. 193-195, 2004.

[42] Y. S. Kwon, K. H. Jang, and I. H. Jang, "The effects of Korean red ginseng (Ginseng Radix Rubra) on liver regeneration after partial hepatectomy in dogs," Journal of Veterinary Science (Suwon-si, Korea), vol. 4, no. 1, pp. 83-92, 2003.

[43] T. Yokozawa, H. Seno, and H. Oura, "Effect of ginseng extract on lipid and sugar metabolism. I. Metabolic correlation between liver and adipose tissue," Chemical and Pharmaceutical Bulletin, vol. 23, no. 12, pp. 3095-3100, 1975.

[44] T. Yokozawa, K. Kanai, M. Takefuji, and H. Oura, "Effect of Ginseng saponin on liver glycogen content," Chemical and Pharmaceutical Bulletin, vol. 24, no. 12, pp. 3202-3204, 1976.

[45] M. Yamamoto, T. Uemura, S. Nakama, M. Uemiya, and A. Kumagai, "Serum HDL-cholesterol-increasing and fatty liver-improving actions of Panax ginseng in high cholesterol diet-fed rats with clinical effect on hyperlipidemia in man," American Journal of Chinese Medicine, vol. 11, no. 1-4, pp. 96$101,1983$.

[46] H. B. El-Serag and K. L. Rudolph, "Hepatocellular carcinoma: epidemiology and molecular carcinogenesis," Gastroenterology, vol. 132, no. 7, pp. 2557-2576, 2007.

[47] S. Helms, "Cancer prevention and therapeutics: Panax ginseng," Alternative Medicine Review, vol. 9, no. 3, pp. 259-274, 2004.

[48] Ginseng-HCC Chemopreventive Study Osaka Group, "Study on chemoprevention of hepatocellular carcinoma by ginseng: an introduction to the protocol," Journal of Korean Medical Science, vol. 16, supplement, pp. S70-S74, 2001.

[49] H. Nishino, H. Tokuda, T. Ii et al., "Cancer chemoprevention by ginseng in mouse liver and other organs," Journal of Korean Medical Science, vol. 16, supplement, pp. S66-69, 2001.

[50] F. Kamangar, Y. T. Gao, X. O. Shu et al., "Ginseng intake and gastric cancer risk in the Shanghai women's health study cohort," Cancer Epidemiology Biomarkers and Prevention, vol. 16, no. 3, pp. 629-630, 2007.

[51] T. K. Yun, "Experimental and epidemiological evidence on non-organ specific cancer preventive effect of Korean ginseng and identification of active compounds," Mutation Research, vol. 523-524, pp. 63-74, 2003. 
[52] T. K. Yun, Y. S. Yun, and I. W. Han, "Anticarcinogenic effect of long-term oral administration of red ginseng on newborn mice exposed to various chemical carcinogens," Cancer Detection and Prevention, vol. 6, no. 6, pp. 515-525, 1983.

[53] H. G. Kim, S. R. Yoo, H. J. Park et al., "Antioxidant effects of Panax ginseng C.A. Meyer in healthy subjects: a randomized, placebo-controlled clinical trial," Food and Chemical Toxicology, vol. 49, no. 9, pp. 2229-2235, 2011.

[54] T. Ramesh, S. W. Kim, J. H. Sung et al., "Effect of fermented Panax ginseng extract (GINST) on oxidative stress and antioxidant activities in major organs of aged rats," Experimental Gerontology, vol. 47, no. 1, pp. 77-84, 2012.

[55] J. Y. Shim, M. H. Kim, H. D. Kim, J. Y. Ahn, Y. S. Yun, and J. Y. Song, "Protective action of the immunomodulator ginsan against carbon tetrachloride-induced liver injury via control of oxidative stress and the inflammatory response," Toxicology and Applied Pharmacology, vol. 242, no. 3, pp. 318-325, 2010.

[56] T. Yokozawa, K. S. Kang, N. Yamabe, and H. Y. Kim, “Therapeutic potential of heat-processed Panax ginseng with respect to oxidative tissue damage," Drug Discovery \& Therapeutics, vol. 1, no. 1, pp. 30-44, 2007.

[57] J. Voces, A. I. Alvarez, L. Vila, A. Ferrando, C. Cabral De Oliveira, and J. G. Prieto, "Effects of administration of the standardized Panax ginseng extract G115 on hepatic antioxidant function after exhaustive exercise," Comparative Biochemistry and Physiology C, vol. 123, no. 2, pp. 175-184, 1999.

[58] S. B. Song, N. H. Tung, T. H. Quang, N. T. T. Ngan, K. E. Kim, and Y. H. Kim, "Inhibition of TNF- $\alpha$-mediated NF$\kappa \mathrm{B}$ transcriptional activity in HepG2 cells by dammaranetype saponins from Panax ginseng leaves," Journal of Ginseng Research, vol. 36, no. 2, pp. 146-152, 2012.

[59] Y. Liu, J. W. Zhang, W. Li et al., "Ginsenoside metabolites, rather than naturally occurring ginsenosides, lead to inhibition of human cytochrome P450 enzymes," Toxicological Sciences, vol. 91, no. 2, pp. 356-364, 2006.

[60] H. U. Lee, E. A. Bae, M. J. Han, N. J. Kim, and D. H. Kim, "Hepatoprotective effect of ginsenoside $\mathrm{Rb}_{1}$ and compound $\mathrm{K}$ on tert-butyl hydroperoxide-induced liver injury," Liver International, vol. 25, no. 5, pp. 1069-1073, 2005.

[61] Y. Wang, X. Ye, Z. Ma et al., "Induction of cytochrome P450 1A1 expression by ginsenoside $\mathrm{Rg}_{1}$ and $\mathrm{Rb}_{1}$ in HepG2 cells," European Journal of Pharmacology, vol. 601, no. 1-3, pp. 7378, 2008.

[62] H. J. Park, K. M. Park, M. H. Rhee et al., "Effect of ginsenoside $\mathrm{RB}_{1}$ on rat liver phosphoproteins induced by carbon tetrachloride," Biological and Pharmaceutical Bulletin, vol. 19, no. 6, pp. 834-838, 1996.

[63] Y. T. Lo, Y. H. Tsai, S. J. Wu, J. R. Chen, and J. C. Chao, "Ginsenoside $\mathrm{Rb}_{1}$ inhibits cell activation and liver fibrosis in rat hepatic stellate cells," Journal of Medicinal Food, vol. 14, no. 10, pp. 1135-1143, 2011.

[64] K. Sakakibara, Y. Shibata, T. Higashi, S. Sanada, and J. Shoji, "Effect of Ginseng saponins on cholesterol metabolism. I. The level and the synthesis of serum and liver cholesterol in rats treated with ginsenosides," Chemical and Pharmaceutical Bulletin, vol. 23, no. 5, pp. 1009-1016, 1975.

[65] M. Ikehara, Y. Shibata, and T. Higashi, "Effect of ginseng saponins on cholesterol metabolism. III. Effect of ginsenoside$\mathrm{Rb}_{1}$ on cholesterol synthesis in rats fed on high-fat diet," Chemical and Pharmaceutical Bulletin, vol. 26, no. 9, pp. 28442849, 1978.
[66] K. H. Park, H. J. Shin, Y. B. Song et al., "Possible role of ginsenoside $\mathrm{Rb}_{1}$ on regulation of rat liver triglycerides," Biological and Pharmaceutical Bulletin, vol. 25, no. 4, pp. 457460, 2002.

[67] J. Geng, W. Peng, Y. Huang, H. Fan, and S. Li, "Ginsenoside$\mathrm{Rg}_{1}$ from Panax notoginseng prevents hepatic fibrosis induced by thioacetamide in rats," European Journal of Pharmacology, vol. 634, no. 1-3, pp. 162-169, 2010.

[68] S. J. Kim, H. D. Yuan, and S. H. Chung, "Ginsenoside $\mathrm{Rg}_{1}$ suppresses hepatic glucose production via AMP-activated protein kinase in HepG2 cells," Biological and Pharmaceutical Bulletin, vol. 33, no. 2, pp. 325-328, 2010.

[69] H. D. Yuan, S. J. Kim, H. Y. Quan, D. Y. Kim, G. W. Kim, and S. H. Chung, "Ginsenoside Re attenuates alcoholic fatty liver disease via regulation of AMPK and MAPK pathways in alcohol-fed ICR mice," in Proceedings of the Spring International Ginseng Conference, p. 114, The Korean Society of Ginseng, Jeju, Korea, April 2012.

[70] H. Y. Quan, H. D. Yuan, M. S. Jung, S. K. Ko, Y. G. Park, and S. H. Chung, "Ginsenoside Re lowers blood glucose and lipid levels via activation of AMP-activated protein kinase in HepG2 cells and high-fat diet fed mice," International Journal of Molecular Medicine, vol. 29, no. 1, pp. 73-80, 2012.

[71] H. D. Yuan, D. Y. Kim, H. Y. Quan, S. J. Kim, M. S. Jung, and S. H. Chung, "Ginsenoside $\mathrm{Rg}_{2}$ induces orphan nuclear receptor SHP gene expression and inactivates GSK3 $\beta$ via AMP-activated protein kinase to inhibit hepatic glucose production in HepG2 cells," Chemico-Biological Interactions, vol. 195, no. 1, pp. 35-42, 2012.

[72] S. H. Cho, K. S. Chung, J. H. Choi, D. H. Kim, and K. T. Lee, "Compound $\mathrm{K}$, a metabolite of ginseng saponin, induces apoptosis via caspase-8-dependent pathway in HL-60 human leukemia cells," BMC Cancer, vol. 9, article 149, pp. 1-13, 2009.

[73] B. C. He, J. L. Gao, X. Luo et al., "Ginsenoside $\mathrm{Rg}_{3}$ inhibits colorectal tumor growth through the down-regulation of Wnt/ $\beta$-catenin signaling," International Journal of Oncology, vol. 38, no. 2, pp. 437-445, 2011.

[74] X. Luo, C. Z. Wang, J. Chen et al., "Characterization of gene expression regulated by American ginseng and ginsenoside $\mathrm{Rg}_{3}$ in human colorectal cancer cells," International Journal of Oncology, vol. 32, no. 5, pp. 975-983, 2008.

[75] J. W. Jiang, X. M. Chen, X. H. Chen, and S. S. Zheng, "Ginsenoside $\mathrm{Rg}_{3}$ inhibits hepatocellular carcinoma growth via intrinsic apoptotic pathway," World Journal of Gastroenterology, vol. 17, no. 31, pp. 3605-3613, 2011.

[76] C. Zhang, L. Liu, Y. Yu, B. Chen, C. Tang, and X. Li, "Antitumor effects of ginsenoside $\mathrm{Rg}_{3}$ on human hepatocellular carcinoma cells," Molecular Medicine Reports, vol. 5, no. 5, pp. 1295-1298, 2012.

[77] G. Song, S. Guo, W. Wang et al., "Intestinal metabolite compound $\mathrm{K}$ of ginseng saponin potently attenuates metastatic growth of hepatocellular carcinoma by augmenting apoptosis via a bid-mediated mitochondrial pathway," Journal of Agricultural and Food Chemistry, vol. 58, no. 24, pp. 12753-12760, 2010.

[78] D. Y. Kim, H. D. Yuan, I. K. Chung, and S. H. Chung, "Compound $\mathrm{k}$, intestinal metabolite of ginsenoside, attenuates hepatic lipid accumulation via AMPK Activation in human hepatoma cells," Journal of Agricultural and Food Chemistry, vol. 57, no. 4, pp. 1532-1537, 2009.

[79] H. U. Lee, E. A. Bae, J. H. Myung, and D. H. Kim, "Hepatoprotective effect of 20(S)-ginsenosides $\mathrm{Rg}_{3}$ and its metabolite $20(S)$-ginsenoside $\mathrm{Rh}_{2}$ on tert-butyl hydroperoxide-induced 
liver injury," Biological and Pharmaceutical Bulletin, vol. 28, no. 10, pp. 1992-1994, 2005.

[80] V. Nobili, C. Carter-Kent, and A. E. Feldstein, "The role of lifestyle changes in the management of chronic liver disease," BMC Medicine, vol. 9, article 70, pp. 1-7, 2011.

[81] N. D. Scott-Luper, "A review of plants used in the treatment of liver disease: part 1," Alternative Medicine Review, vol. 3, no. 6, pp. 410-421, 1998.

[82] C. Loguercio and D. Festi, "Silybin and the liver: from basic research to clinical practice," World Journal of Gastroenterology, vol. 17, no. 18, pp. 2288-2301, 2011. 


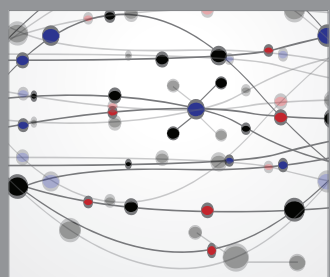

The Scientific World Journal
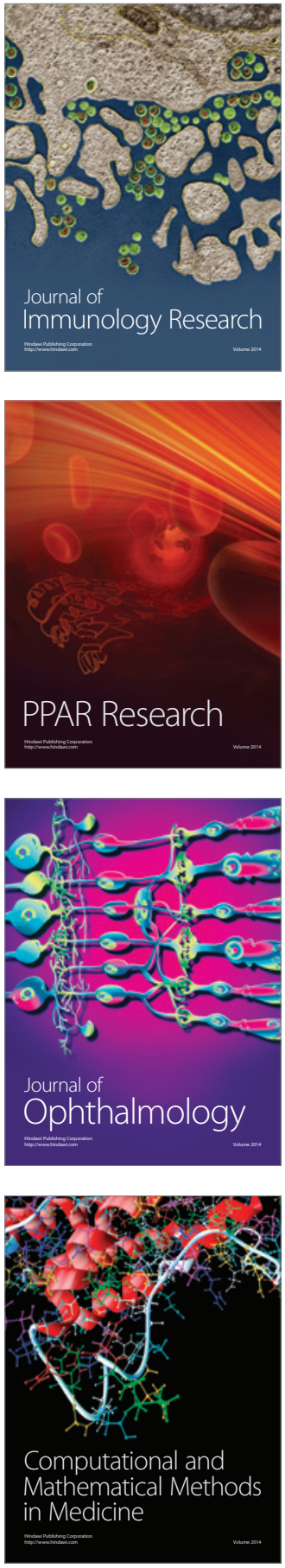

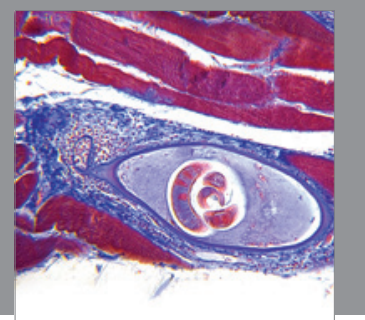

Gastroenterology

Research and Practice
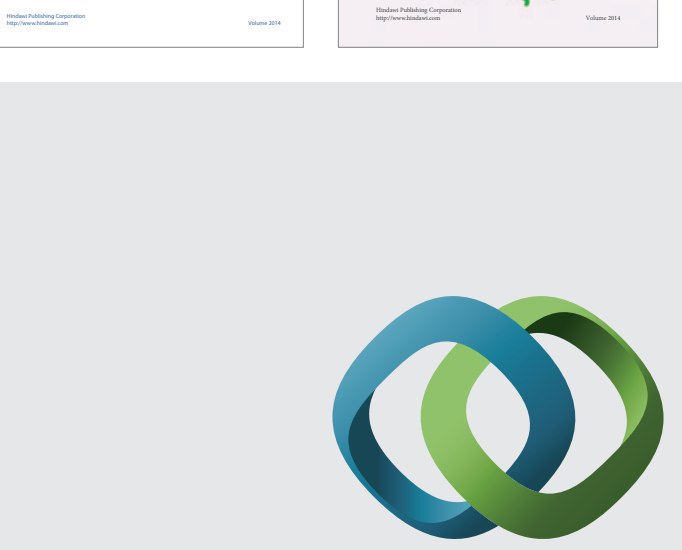

\section{Hindawi}

Submit your manuscripts at

http://www.hindawi.com
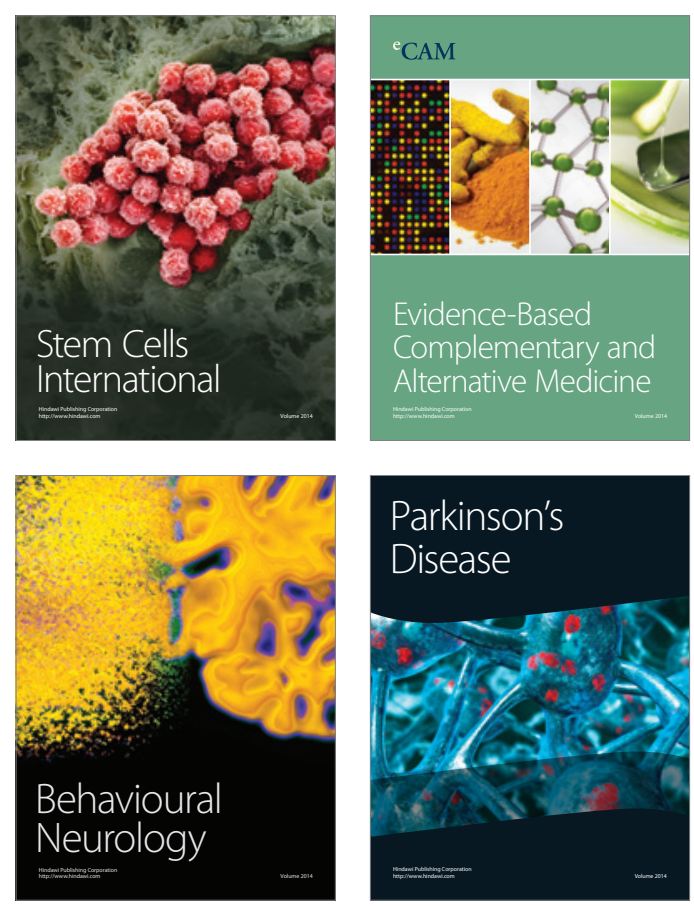

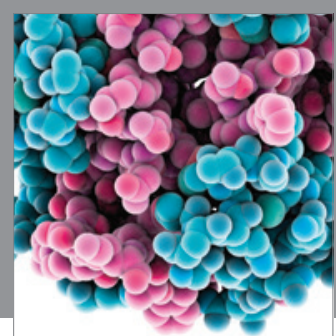

Journal of
Diabetes Research

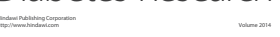

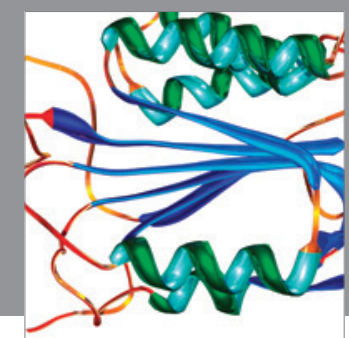

Disease Markers
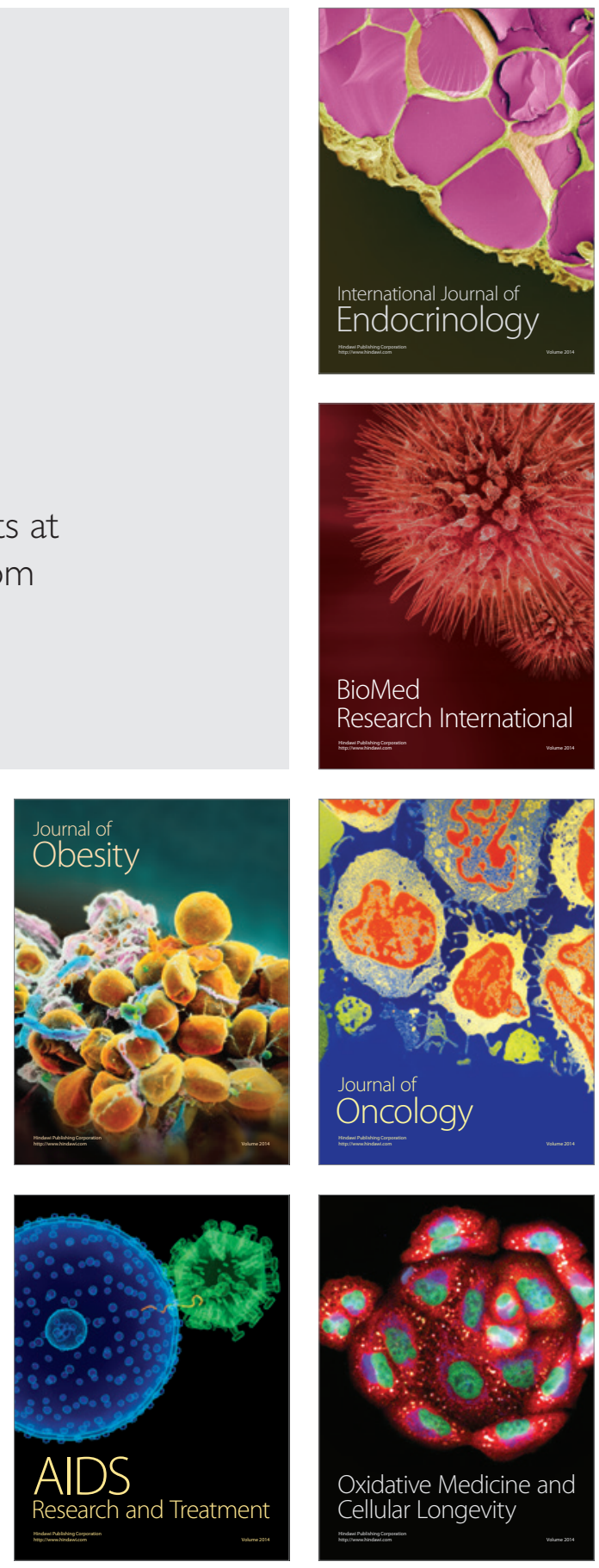